\title{
Skilful anticipation: maternity nurses' perspectives on maintaining safety
}

\author{
A Lyndon
}

Department of Family Health Care Nursing, University of California, San Francisco, School of Nursing, San Francisco, California, USA

\section{Correspondence to} Assistant Professor Audrey Lyndon, University of California, San Francisco, 2 Koret Way, Box 0606, San Francisco, CA 94143 USA; audrey.lyndon@ucsf.edu

Accepted 4 June 2009 Published Online First 8 February 2010

\begin{abstract}
Objective To describe maternity nurses' perspectives on how they contribute to safety during labour and birth at two urban academic medical centres in the United States.

Design Grounded theory: data were collected using semistructured, open-ended interviews and participant observations with registered nurses (RNs) in two inpatient maternity settings. Data were analysed simultaneously using constant comparison, and dimensional and situational analysis.
\end{abstract}

Participants Purposive sample of 12 RNs working in the two maternity units.

Findings Safety was broadly conceptualised by RNs as protecting the physical, psychological and emotional wellbeing of a woman and her family. During labour and birth, safety was maintained by RNs through "skilful anticipation" of situational potential. This required integration of medical and technical knowledge and skill with intimate knowledge of the woman and the operational context of care to achieve accurate situation awareness and appropriate future planning. Conditions and processes promoting skilful anticipation included being prepared, knowing, and envisioning the whole picture.

Conclusions In the two settings, maternity RNs made active contributions to safe birth in the context of constrained resources through preparing the environment, anticipating potential problems and trapping errors before they reached the patient. The contributions of maternity nurses to team situation awareness and to creating safety need to be appreciated and administratively supported. Continued research with RNs may reveal previously unrecognised opportunities for safety improvements.

Rochlin ${ }^{1}$ and others ${ }^{2}$ proposed that a narrow focus on systems risk reduction interferes with maintaining safe operations by obscuring ongoing individual and collective actions that detect and correct emerging safety threats. Rochlin's analysis suggests that high reliability is achieved through an emergent social construct of collective agency for safety, and that supporting this collective behaviour is essential. $\mathrm{Knox}^{3}$ and Henneman ${ }^{4}$ similarly conceptualised patient safety as a dynamic process of healthcare providers creating safety by identifying and deflecting potential threats to patients. Opportunities for increasing safety may be irretrievably lost when we focus primarily on the incidence and mechanisms of error at the expense of focussing on clinicians' safety-creating actions. ${ }^{2}$ Consideration of safety as an active front-line process suggests the need to understand clinicians' experiences of how patient safety is both created and challenged in healthcare settings. ${ }^{5}$ This is particularly important in maternity care, in which severe adverse events are believed to be substantially preventable ${ }^{6-10}$ yet the infrequency of catastrophic outcomes creates considerable space for normalisation of deviance. ${ }^{11} 12$

Breakthroughs in aviation safety were based in part on understanding challenges to performance from the pilots' perspective. ${ }^{13}$ Few studies have explored healthcare providers' perspectives on how they maintain safe operations. Even fewer have focused on nurses. The purpose of this article is to describe maternity nurses' perspectives on how they contribute to safety during labour and birth These findings are from a larger exploratory descriptive study of facilitators and barriers to interdisciplinary teamwork and effective communication in two inpatient maternity settings in the western USA. ${ }^{14}$

\section{DESIGN AND METHODS}

Grounded theory, a qualitative method for studying social processes, ${ }^{15-19}$ was chosen for this study given the conceptualisation of safety as a social construct and the interest in uncovering participants' experiences of working to promote safety. Data were collected between September 2005 and January 2007 using individual semistructured, open-ended interviews and participant observation with a purposive sample of 12 maternity registered nurses (RNs) from two teaching hospitals. Interviews lasted 60 to $90 \mathrm{~min}$. They were recorded, transcribed verbatim and crosschecked for accuracy. ${ }^{20}$ Forty-four hours of observations with RNs were conducted across day, night and weekend shifts by shadowing participants conducting their clinical duties. Other staff and the patients receiving care gave verbal consent for observations. Field notes were taken during observations and transcribed as soon as possible thereafter. ${ }^{21}$ This report focuses on the perspective of the 12 RN participants; however, physicians and certified nurse midwives were also sampled to obtain a broader perspective on team function, interdisciplinary communication and collective practice. ${ }^{14}$ Participants were selected for clinical experience and likelihood of being able to respond to the study questions. Five RNs participated through interviews only. Seven RNs participated in both interviews and observations. Observations balanced the retrospective nature of interviews by capturing real-time data about communication patterns, work conditions and teamwork. The interview guide and observation protocol are presented in table 1.

Participating institutions gave ethics committee approval. Participants were recruited at staff meetings and by peer nomination, gave informed 
Table 1 Interview guide and observation protocol

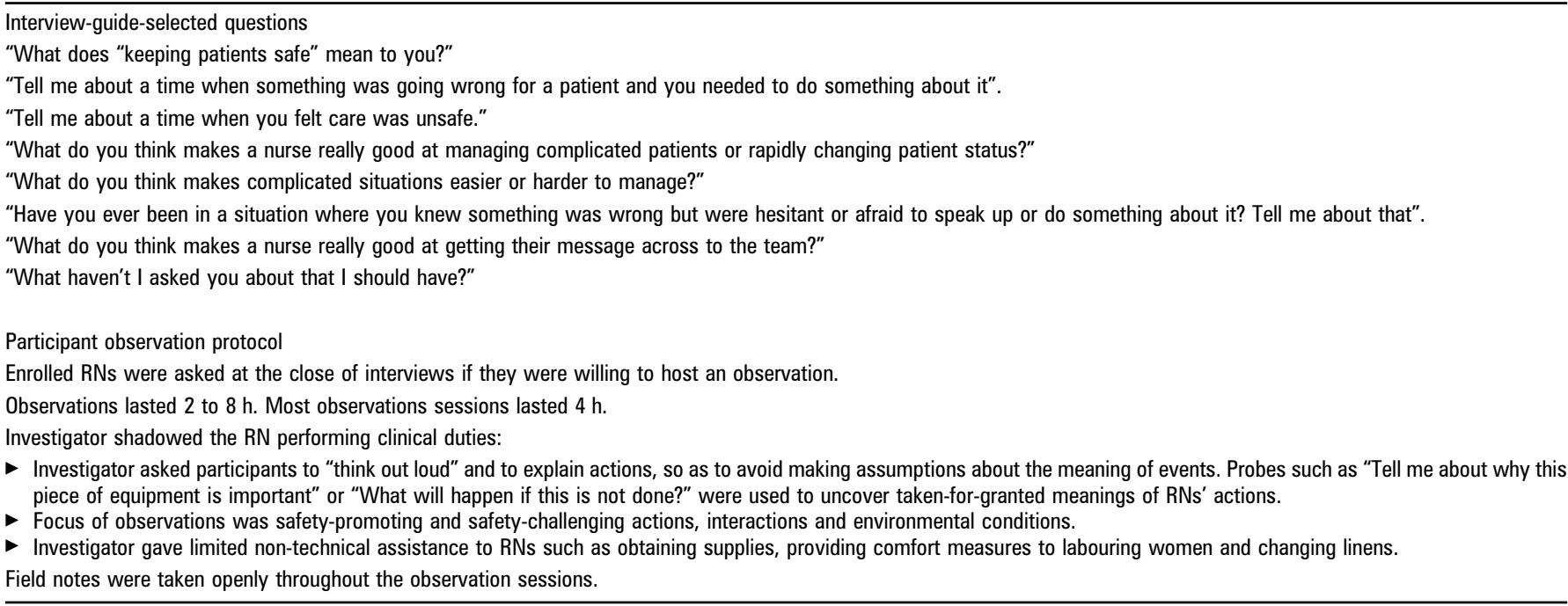

consent before enrolment and received a US\$15 gift card for interviews and observations. Reflexivity, attention to interaction quality, data and analytic triangulation, and use of an audit trail maintained rigour, as described elsewhere. ${ }^{14}$

\section{Settings}

RNs were recruited from the maternity units of two urban teaching hospitals in the western USA. In both units, staff cared for medically and socially complex populations of antepartum, labouring and postpartum women. Both services offered midwifery, generalist and maternal-foetal medicine care; intensive care nurseries; and 24-h in-house obstetric ("labourist") and anaesthesia services. They had between 1200 and 1800 annual births.

\section{Participants}

This sample included 12 experienced RNs. The mean duration of their maternity experience and the mean tenure in their current position were both 10 years (range 0.5 to 41 and 2 to 20 years, respectively). Six RNs worked permanent day shift. Three worked day shift but rotated regularly to nights. Three worked evenings or nights. Shifts were $12 \mathrm{~h}(\mathrm{n}=8)$ or $8 \mathrm{~h}(\mathrm{n}=4)$. Mean age was 42.7 years (range 29 to 61 years). All the RNs were women. Self-reported ethnicity was 75\% European American, 17\% Latina and $8 \%$ Asian Pacific Islander.

\section{Data analysis}

Data were collected and analysed simultaneously using the constant comparative method, and dimensional and situational analysis. ${ }^{14}{ }^{16-18}$ Open, focused and theoretical codes ${ }^{19}$ were used to identify and label dimensions of participants' experience, ${ }^{16}$ which were then saturated through theoretical sampling to develop and differentiate their properties. ${ }^{16} 171922$ Data were managed with Atlas.ti V.5.0-5.2. ${ }^{23}$

In dimensional analysis, the central action process is determined by organising the important dimensions of experience in an "explanatory matrix". The dimension that best explains the central action process is placed in the defining position, called "perspective", and other important dimensions are then evaluated for their fit as context, conditions, processes or consequences. ${ }^{1622}$ Thus, the central action process provides the perspective for understanding relationships between important concepts in the data set. Context is the set of dimensions representing the situation in which the phenomenon is embedded. Conditions are dimensions that facilitate, block or shape central actions, interactions or processes. Processes are actions (intended or unintended) set in motion by conditions, and consequences are outcomes of these processes. ${ }^{16} 22$

\section{RESULTS}

RNs in this study conceptualised safety broadly: a woman was kept safe when she experienced coming through the birth process intact physically, emotionally and psychologically. This did not necessarily mean that the woman's birth met all her expectations. It meant that a woman had the information and time needed to make her own decisions, her physical and emotional needs were met, and she and her family members were treated with respect and consideration. The dimension "skilful anticipation" was the action process with the greatest power to explain the RNs' perspective on their work to prevent harm and promote "coming through the experience intact".

\section{Skilful anticipation}

Skilful anticipation describes the active, accurate consideration of the potential embedded in clinical situations: it includes accurate situation awareness and appropriate future planning. Skilful anticipation required integration of experience, medical and technical know-how, and knowledge of both the individual woman and the operational context of her care. It involved both grasping the current situation and active consideration of (1) what may evolve in the future under this particular set of clinical conditions? (2) What is necessary to prepare for the situational possibilities and support the desired physiologic, psychological and emotional outcomes for this family's birth process? Participants used being prepared, knowing, and envisioning the whole picture (figure 1) to develop a projected future state for women that allowed them to anticipate needs and predict outcomes of care.

Skilful anticipation allowed nurses to prepare independently for patient safety: RNs frequently described and demonstrated being prepared for action before other clinicians recognised or communicated the urgency of a situation. They also described persisting with essential preparations when they perceived an urgent need for intervention and their judgement was initially discounted but ultimately validated. 


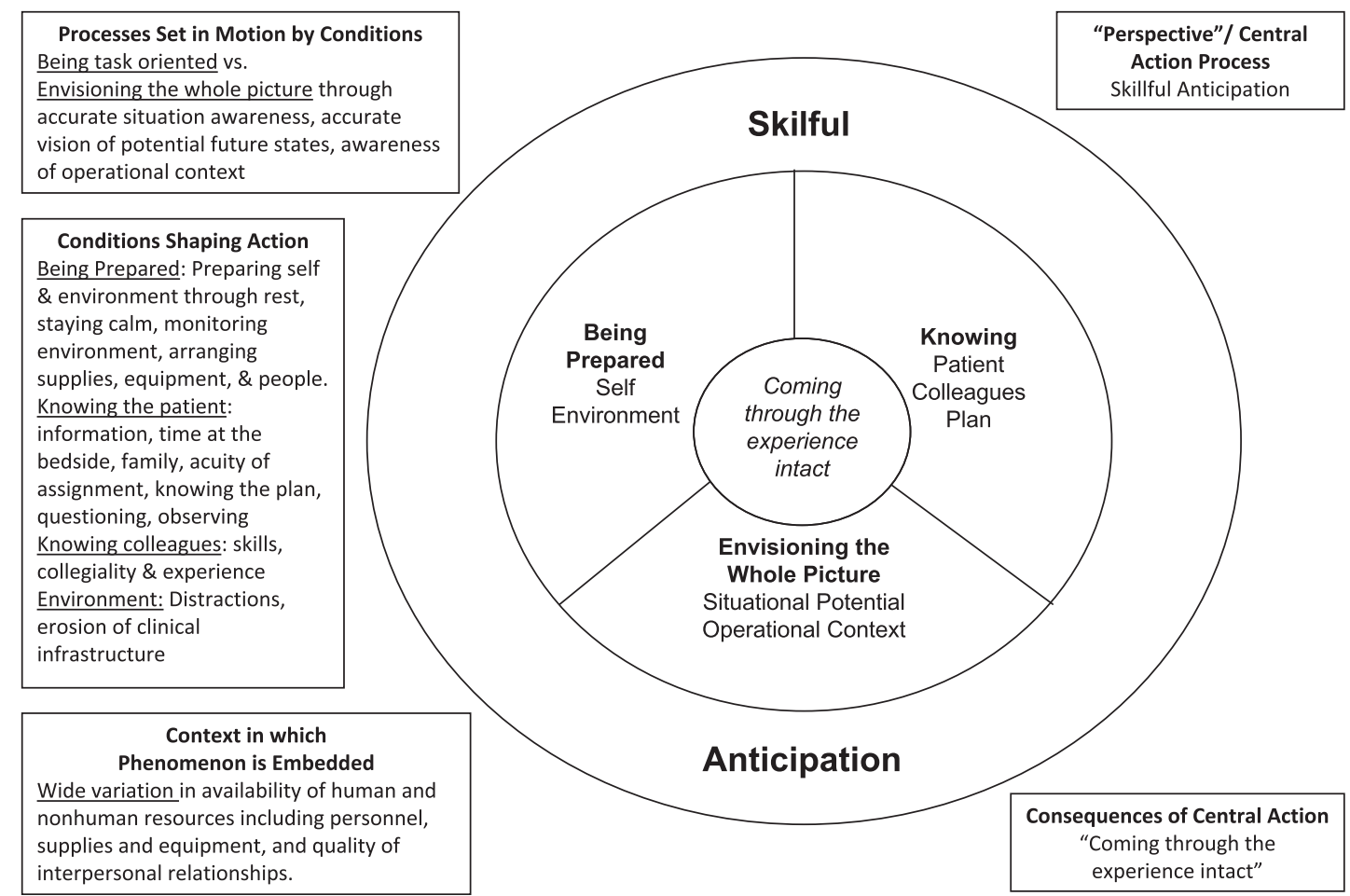

Figure 1 Skilful anticipation: the central action process supporting women coming through the experience intact.

I alerted the doctors, who kind of pooh-poohed me and didn't come in there as fast as I wanted them to... I just threw in an IV and drew the bloods and got her ready...did everything I knew needed to be preliminary before we could even get into the OR [for caesarean birth] (RN, discussing a case resulting in emergent caesarean birth).

\section{Conditions promoting skilful anticipation}

\section{Being prepared: preparing self and preparing the environment}

Both mental and physical preparedness were required to maintain a state of readiness for birth. Most nurses described specific strategies for maintaining mental sharpness, including getting enough sleep, taking breaks in specific locations and minimising distractions. Some denied being affected by stressors such as fatigue, reporting that adrenaline kicks in to keep them sharp when needed.

Birth is a natural process that usually occurs without need for specific intervention. However, catastrophic complications requiring rapid intervention are possible. Preparing the environment entailed arranging the room for action and readying safety supplies. This meant ensuring that equipment was immediately at hand and the bed could quickly be removed to transport the woman to the operating room: untangling monitor cables, IV lines and phone cords; moving furniture to maintain a clear path to the door; and assessing the position of family members to simultaneously support their participation and keep pathways clear. RNs check all emergency equipment in detail to ensure correct functioning. Attention to baseline preparation required integration of technical knowledge of equipment with medical knowledge of birth and potential complications to understand the purpose of the equipment, how it would be used and the consequences of improper set-up. This field note typifies the RNs I observed caring for labouring women:

[Field note] She checks [the mother's] ambu bag and shows me how the holes on the valve are set too far open for fast inflation. She adjusts the bag to fill quickly so "you're not wondering what's going on and fiddling with it when you need to use it". She checks the suction regulator, setting the continuous suction to $100 \mathrm{~mm} \mathrm{Hg}$ so it will be ready for suctioning meconium from baby's airway. She reviews the delivery table set-up. She checks the baby warmer...rearranges [jumbled] supplies in the drawer, sorting ET [endotracheal] tubes by size most often used to the front. She removes extraneous supplies...checks laryngoscope blades. The long blade does not work, there is no bulb. She replaces the blade...She checks the baby's ambu bag and suction...setting valves so bag inflates quickly and has a cpap [continuous positive airway pressure] setting of 5 ...She checks that tanks have oxygen...checks emergency medication supply.

These "routine" tasks frequently trap errors. In each of the five times I observed RNs checking a baby warmer, there was a mistake in some part of the set-up, usually the ambu bag. Maternal ambu bag set-ups were faulty during two observations. This produced a sense of urgency about checking equipment immediately for each patient:

Time is of the essence when you're doing an emergency resuscitation for baby or mother...one of the worst things is going into a situation fast and not having enough time to make sure those things are in place... and you're grabbing for the bag and it's not hooked up (RN).

In most cases, this urgency about being prepared was safety promoting: it sets the tone for methodical, advance preparations promoting smooth team function at birth. However, at times, the urgency to prepare, coupled with lack of confidence in the systems supporting that preparation, results in an obsessive focus on organising equipment. In a least one case, failure to follow-up on critical laboratory results appeared causally related to the intensity of the nurse's focus on preparation. This incident was aggravated by a heavy patient assignment and distraction by missing supplies and broken equipment.

\section{Knowing}

Skilful anticipation was enhanced when RNs had time to gain a complete understanding of the woman's situation. Knowing 
the patient was a function of information (knowledge of the patient's history and plan), temporality (time spent with the patient to obtain knowledge of her responses) and assessing family dynamics. Knowing the patient laid the groundwork for addressing potential problems by allowing RNs to anticipate complications with labour, birth, postpartum, breastfeeding or family. Most importantly, time at the bedside promoted successful rescue from complications. When RNs were able to engage in direct continuous surveillance, they identified subtle changes in condition and mobilised the team to respond to emergent issues such as a high epidural block and an unusual medication reaction.

For these nurses, knowing the patient meant understanding the whole of the plan, not mechanically executing ordered care:

\section{Making sure I'm aware of who's seeing her [each patient], what orders are being written about her, what's being asked of me, what everything means as far as orders and plans, and keeping communication open (RN)}

RNs were keenly aware that MDs and CNMs looked to them to be very familiar with a woman's immediate situation in labour and to provide up-to-date information. To know the patient well, RNs needed quality hand-off reports, time to review the history and the chart, and time to spend at the bedside. Time was almost universally constrained, requiring integration of preparations with getting acquainted with a woman and her family. RNs were adept at this integration, but high acuities, high census, and problems with equipment, supplies or medication could disrupt safety by disrupting this process.

\section{Knowing the colleague}

Familiarity with specific clinicians and variations in levels of expertise were important to all participants. RNs gained insight about what to expect from understanding individual practice styles and used this to project how others might manage specific situations. RNs varied their communications and their acceptance of specific plans based on their perceptions of an MD's or a CNM's skills, collegiality and experience. RNs were very directive with inexperienced clinicians, especially at birth and in urgent situations:

[Field note] The intern comes to recheck the patient. She is unsure whether she feels cervix or [umbilical] cord and asks the nurse to get the chief. [The nurse] reminds the intern to keep her hand in the vagina and put pressure on the foetal head. She calls out on the intercom, requesting both the chief and attending come to the room. She immediately checks the bed for tangles and lines [thinking about getting the patient out of the room in a hurry].

\section{Envisioning the whole picture}

The key process enabling skilful anticipation to occur was envisioning the whole picture. One $\mathrm{RN}$ remarked, "It's like, switching gears from just doing what's in front of your nose, and seeing that what's in front of your nose has wings. And you have to anticipate, prepare and follow through on a bigger thing going on". This was easier when RNs had resources and time to prepare the environment and get to know the patient. A collegial relationship with the MD or CNM also enhanced information flow and contributed to anticipating situational potential. Envisioning the whole picture was not always dependent on knowing the patient or situation, "I could tell by just looking on the floor, even though I didn't have the full picture of what was going on. This was an excessive amount of blood she'd lost". However, it was enhanced when time and information were available. It was facilitated by awareness of the operational context of care, meaning the RN's understanding of the whole of what was happening on the unit, especially under the common circumstances of competing demands and limited staff.

Although RNs were skilled at obtaining resources and expertise to address problems, they were clear that at times, keeping patients safe meant new activities could not be initiated due to resource constraints. In both interview and observational data, $\mathrm{RNs}$ demonstrated a heightened awareness relative to $\mathrm{MDs}$ regarding the operational and surveillance demands of patient care.

So I said, "The person will be admitted, but she cannot have miso [prostol] or Pitocin". [uterotonic agents for induction of labour] [The doctor] was shocked because [to the doctor they are] just giving some medication. I'm thinking, "No, there has to be a nurse to watch that [foetal heart monitor] strip and make sure that baby is handling whatever's going on in response to mama receiving the miso, plus mama". And that would be me. And that is not safe. It's not safe to have me [doing three jobs] at the desk as charge, in triage, and watching somebody who just got miso. So no, we're not doing it $(\mathrm{RN})$.

\section{DISCUSSION}

This study aims to describe maternity nurses' perspectives on their contributions to safety during labour and birth. Skilful anticipation emerged as the central action process RNs use to actively promote safe birth. They demonstrated using being prepared, knowing, and envisioning the whole picture to prepare the environment, anticipate problems and trap errors in the context of multiple problems with basic resources for staffing, supplies and equipment. Knowledge of individual women and the operational context of care were needed for skilful anticipation of physical, psychological and emotional safety needs. Even "checking equipment" used critical medical and technical knowledge to anticipate and mitigate potential safety threats, and contributed to situation awareness. These behaviours illustrate some of the RNs' contributions to maintaining safety and team situation awareness. They are consistent with descriptions of RN engagement in error trapping, surveillance and serving as a "firewall and protector" in the critical care and emergency departments. ${ }^{24} 2530$ They support the concepts of safety as an active process and of the healthcare provider's role in creating safety through scanning for, detecting and correcting potential sources of harm.

The limitations of the study include small sample size, selection bias, recall bias and attribution error. The study was conducted with 12 nurses and cannot be construed as representative of maternity nurses in general. Non-participants may have different conceptualisations of the meaning of safe care and their role(s) in providing it. Interview data are subject to recall bias. Clinicians' knowledge of case outcomes influences perceptions of contributing factors ${ }^{26}$ : clinicians are more likely to attribute successes to their own disposition while attributing failures to situational factors. ${ }^{27}$ Most participants frankly discussed their own mistakes and clinical mishaps, diminishing concern for social desirability bias. The investigator's maternity nursing background also may have biased analysis. Mitigation strategies included journaling, exposing taken-for-granted meanings and testing experiential data against grounded field data. $^{14} 1728$

The behaviours and constraints described in this study may not be unique to maternity care or to RNs. The study highlights some of the complexity involved in maintaining situation 
awareness in inpatient settings and suggests the need to spend more time studying action on the front line where safety is ultimately threatened or maintained. Institutional support in the form of time and functional equipment are essential for clinicians to engage in safety-promoting behaviours consistently and effectively. ${ }^{29} 30$ Effective support requires valuing contributions to safety from all clinicians and attending to practice infrastructure. Instituting systematic interdisciplinary updates throughout each shift could help all maternity providers maintain awareness of the operational context and availability of resources on the unit. ${ }^{31}$ Before making resource allocation decisions, upper-level managers could combine executive walk rounds ${ }^{32}$ and shadowing ${ }^{33}$ to conduct "executive work rounds", where directors work side by side with clinicians to gather firsthand evidence of vulnerabilities, strengths and threats to resilience at unit and system levels.

Interdisciplinary research is needed to better understand how nurses and other clinicians contribute to patient safety, and to link these contributions to safety outcomes. Research on frontline safety perspectives may reveal unrecognised opportunities for safety improvements, identify how to support collective safety behaviours without creating new gaps in communication and teamwork, ${ }^{34}$ and point to ways that behaviours and systems thought to be safety promoting can present threats to safety when they alter team behaviours ${ }^{34}$ or suppress reporting. ${ }^{14}$

Acknowledgements The author thanks the participants for their time, energy and trust; the editors and reviewers for their constructive critique; and Drs K Lee, H P Kennedy, B Davies, K R Simpson and L Fischer for comments on previous drafts. The study was funded by the Association of Women's Health, Obstetric and Neonatal Nurses, and supported by the Nursing Initiative of the Gordon and Betty Moore Foundation.

Funding Association of Women's Health, Obstetric and Neonatal Nurses (2000 L Street, NW, Suite 740, Washington, DC 20036, USA), and Gordon and Betty Moore Foundation (Presidio of San Francisco, P0 Box 29910, San Francisco, CA 94129-0910, USA).

\section{Competing interests None.}

Ethics approval This study was conducted with the approval of the University of California, San Francisco.

Provenance and peer review Not commissioned; externally peer reviewed.

\section{REFERENCES}

. Rochlin GI. Safe operation as a social construct. Ergonomics 1999:42:1549-60.

2. Woods DD, Cook RI. Mistaking error. In: Youngberg BJ, Hatlie M, eds. The patient safety handbook. Sudsbury: Jones and Bartlett, 2004:95-108.

3. Knox GE. Beyond high reliability: moving to ultrasafe systems. Kaiser Permanente partnership for perinatal patient safety conference October 2003. San Francisco: 2003.

4. Henneman EA, Gawlinski A. A "near-miss" model for describing the nurse's role in the recovery of medical errors. J Prof Nurs 2004;20:196-201.

5. Lyndon A. Communication and teamwork in patient care: how much can we learn from aviation? J Obstet Gynecol Neonatal Nurs 2006:35:538-46.

6. JCAHO. Sentinel event statistics, September 30 2007. 2007. http://www. jointcommission.org/SentinelEvents/Statistics/ (accessed 27 Dec 2007).
7. JCAHO. Preventing infant death and injury during delivery. Sentinel Event Alert 2004;30:1-3.

8. USDHHS. Healthy people 2010. 2nd rev ed. With understanding and improving health objectives for improving health. Washington, DC: U.S. Government Printing Office, 2000.

9. Geller SE, Rosenberg D, Cox SM, et al. The continuum of maternal morbidity and mortality: factors associated with severity. Am J Obstet Gynecol 2004;191:939-44.

10. Kilpatrick SJ, Crabtree KE, Kemp A, et al. Preventability of maternal deaths: comparison between Zambian and American referral hospitals. Obstet Gynecol 2002;100:321-6.

11. Knox GE, Simpson KR, Garite TJ. High reliability perinatal units: an approach to the prevention of patient injury and medical malpractice claims. J Healthc Risk Manag 1999;19:24-32.

12. Simpson KR, James DC, Knox GE. Nurse-physician communication during labor and birth: implications for patient safety. J Obstet Gynecol Neonatal Nurs 2006;35:547-56

13. Helmreich RL, Foushee HC, Benson R, et al. Cockpit resource management: exploring the attitude-performance linkage. Aviat Space Environ Med 1986;57:1198-200

14. Lyndon A. Social and environmental conditions creating fluctuating agency for safety in two urban academic birth centers. J Obstet Gynecol Neonatal Nurs 2008:37:13-23.

15. Glaser BG, Strauss AL. The discovery of grounded theory: strategies for qualitative research. Hawthorne (NY): Aldine De Gruyter, 1967.

16. Schatzman L. Dimensional analysis: notes on an alternative approach to the grounding of theory in qualitative research. In: Maines DR, ed. Social organization and social process: essays in honor of Anselm Strauss. New York: Aldine de Gruyter, 1991:303-14.

17. Strauss AL. Qualitative analysis for social scientists. Cambridge: Cambridge University Press, 1987

18. Clarke AE. Situational analysis: grounded theory after the postmodern turn. Thousand Oaks: Sage, 2005.

19. Charmaz K. Constructing grounded theory. Thousand Oaks: Sage, 2006

20. Kvale S. InterViews: an introduction to qualitative research interviewing. Thousand Oaks: Sage, 1996

21. Hammersley M, Atkinson P. Ethnography: principles in practice. 2nd rev ed. New York: Routledge, 1995.

22. Kools S, McCarthy M, Durham R, et al. Dimensional analysis: broadening the conception of grounded theory. Qual Health Res 1996:6:312-30.

23. Muhr T. Atlas.ti. 5.0-5.2 rev ed. Berlin: Scientific Software Development GmbH, 2004.

24. Rothschild JM, Hurley $\mathrm{AC}$, Landrigan $\mathrm{CP}$, et al. Recovery from medical error: the critical care nursing safety net. Jt Comm J Qual Patient Saf 2006;32:63-72.

25. Henneman EA, Blank FSJ, Gawlinski A, et al. Strategies used to recover medical errors in an academic emergency department setting. App/ Nurs Res 2006;19:70-7.

26. Dekker S. The field guide to human error investigations Burlington: Ashgate, 2002.

27. Henricksen $\mathbf{K}$, Dayton E. Organizational silence and hidden threats to patient safety. Health Serv Res 2006;41:1539-54.

28. Angen MJ. Evaluating interpretive inquiry: reviewing the validity debate and opening the dialogue. Oual Health Res 2002:10:378-93.

29. Page A. Keeping patients safe: transforming the work environment of nurses Washington, DC: National Academy Press, 2004.

30. Benner P, Hooper-Kyriakidis P, Stannard D. Clinical wisdom and interventions in critical care: a thinking in action approach. Philadelphia: Saunders, 1999.

31. Thompson D, Holzmueller C, Hunt D, et al. A morning briefing: setting the stage for a clinically and operationally good day. Jt Comm J Qual Patient Saf 2005;31:476-9.

32. Thomas EJ, Sexton JB, Neilands TB, et al. Correction: the effect of executive walk rounds on nurse safety climate attitudes: a randomized trial of clinical units. [ISRCTN85147255]. BMC Health Serv Res 2005;5:46.

33. Thompson DA, Holzmueller CG, Lubomski L, et al. View the world through a different lens: shadowing another provider. Jt Comm J Qual Patient Saf 2008;34:614-18, 561

34. Beuscart-Zephir MC, Pelayo S, Anceaux F, et al. Cognitive analysis of physicians and nurses cooperation in the medication ordering and administration process. Int J Med Inform 2007;76(Suppl 1):S65-77. 